\title{
The Optimality of Tax Transfers: What does Life Satisfaction Data tell us? ${ }^{1}$
}

\author{
Paul Frijters*, David W. Johnston** and Michael A. Shields*** \\ * University of Queensland, Brisbane, Australia \\ ** Monash University, Melbourne, Australia \\ *** University of Melbourne \& Monash University, Melbourne, Australia
}

\footnotetext{
${ }^{1}$ Corresponding author: David W. Johnston, Centre for Health Economics, Monash University, Clayton, Victoria, 3800, Australia. Email: david.johnston@monash.edu.
} 


\begin{abstract}
This paper addresses an important policy question: who gets the largest utility gain from income and does the tax system adequately reflect this? We address this question by using Australian panel data and taking life satisfaction as a proxy for utility, allowing us to identify the marginal utility of additional income for different groups of individuals. We find that optimal transfers consist of transfers from the old to the middle aged, and from the married to the unmarried. This optimal utilitarian welfare policy is then contrasted with information on who actually receives transfers and who pays for them in Australia, where we find that taxes are too high for some groups, like the young, and that they are too low for other groups, like the elderly. We believe that the methodology developed in this paper could be fruitfully applied to the issue of optimal taxation in other countries.
\end{abstract}




\section{Introduction}

The interest amongst economists in observable measures of utility, rather than presumed functions of utility, has increased dramatically in recent years. Life satisfaction in particular has emerged as a simple and widely used proxy for utility, available for large samples of survey respondents in multiple countries. It has been, and continues to be, commonly used in empirical economic analyses (reviews can be found in Frey and Stutzer, 2002; Di Tella and MacCulloch, 2006; and Clark et al., 2008). Recent economic applications using life satisfaction data are the costing of drought (Carroll et al., 2009), terrorism (Frey et al., 2007, 2009), commuting (Stutzer and Frey, 2008), chronic disease (Ferrer-i-Carbonel and van Praag, 2002), volunteering (Meier and Stutzer, 2008), bureaucratic rents (Luechinger et al., 2008) and airport noise (van Praag and Baarsma, 2005). In this paper we contribute to this growing literature by using life satisfaction responses to explore one of the key issues of government: who should be taxed for the benefit of whom? While this paper focuses on Australian data and the Australian tax system we believe that our approach could be reasonably applied to data from other countries.

The basic idea of the paper is to take life satisfaction as a measure of experienced utility and to wonder what the transfers between households should be such that aggregate life satisfaction is highest. Once one accepts it as a reasonable approximation that life satisfaction is a linear transform of experienced utility, the question of optimal transfers then becomes the question of how to redistribute from those that have low marginal life satisfaction of money to those that have a high marginal life satisfaction of money (cf. Layard et al. 2008).

The literature on optimal taxation is vast and keenly aware of distortions. For Mirlees (1971) and others working on optimal taxation, the wish to redistribute from those with low marginal utility of income to those with high marginal utility of income has to be balanced with the danger of tax avoidance. Individuals will try to avoid taxation by altering their labour supply, which reduces the amount of earned money available to be taxed in the first place. When taken to its logical conclusion, Mirlees showed that the most talented individual should be completely untaxed on the last dollar she makes in order for her to retain the incentive to make that dollar (see, also, Saez 2001).

The classic 'solution' to the ensuing conundrum is to tax things that cannot run away and re-distribute the proceeds to the poor. Tinbergen (1970) therefore proposed a tax on 'talent' since talent does not change. Plug et al. (1999) attempted to calculate how high such a talent tax should have to be, using a Dutch dataset with information on income and IQ. In this exercise the authors acknowledge that if talent were truly used as a basis for taxation, then 
individuals might endeavour to have their talent mismeasured. Nevertheless, the basic insight that tax evasion brings distortions is a key reason for economists to argue for taxation on relatively inelastic goods, such as land and consumption (see, for example, Faulk et al. 2007).

Our purpose in this paper is in a similar vein as the Tinbergen talent tax idea and the Mirlees tax schedule: we set up a thought experiment that tells us what the 'life satisfaction optimising' transfer schedule would have to be under certain assumptions. We can then compare the results of that experiment with the actual transfers observed in a society in order to get an idea of how close the actual tax system already is to this idea.

The main 'novel' element in our approach is to use cross-sectional and panel data information to tell us about the marginal utility of income enjoyed by different individuals. This leads to potentially different optimal tax schedules than the classic optimal tax literature, where each individual has the same utility function with respect to income and hence marginal utilities differ only between poor and rich individuals (e.g. Saez 2001). The resulting optimal taxation is then mainly a function of the elasticities of labour supply, with the general rule that those whose supply of labour is inelastic should be taxed the heaviest. Given the consensus in the labour market literature that prime-aged men have the lowest elasticities, and women, the young and those nearing pension age have the highest elasticities (see, for example, Borjas 2004), it follows that the optimal taxes resulting from this alternative line of thinking are on prime-aged men with the proceeds going to the poorest.

Of course, the reality of the tax and welfare system is more highly complicated. For Australia, for example, the stylised situation is that the main group taxed is prime-aged men (and their households) with proceeds going to single women, the elderly and the young, but it is simultaneously the case that the highest marginal disincentive to work falls on the wrong groups. That is, it falls on single women with children and those close-to-pension aged individuals who are generally believed to have relatively high labour supply elasticities (see Frijters and Gregory, 2006).

Our data comes from the Household, Income and Labour Dynamics in Australia Survey (HILDA). We focus on groups defined by age, marital status, children, disability and urban versus rural locations, as the tax system already provides large transfers between these groups. We then calculate the resulting optimal transfer levels, which we do both under the assumption that we can use lump-sum taxes and transfers and under the assumption that any positive transfers have to be paid from a given marginal tax schedule. To identify the net loss via incentives from marginal taxes we use the best estimates available in the literature on the Laffer curve. 


\section{Optimal Taxation and Life Satisfaction}

\section{i. Non-distortionary transfers}

We first work out what optimal transfers would be if there was an all-knowing social planner who has the ability to pre-commit beforehand on transfers between people. One reason why this is unrealistic is that it includes the possibility that people are effectively taxed near or over $100 \%$ of their income. Nevertheless, as a mind experiment it is a very useful device since it rules out any barrier to the level of taxation (i.e. negative transfers), such as via behavioural changes. In a second version of the model we introduce such distortions.

The simplest model of optimal taxation is one in which individuals differ with respect to their marginal utility of income and where lump-sum transfers between individuals to maximise overall welfare can be used. To describe this, take the utility $U$ of an individual $i$ to be represented by a common function:

$$
U_{i}=u_{1}\left(\alpha_{i}\left(Y_{0 i}+w_{i} l_{i}+T_{i}\right)\right)-l_{i}
$$

where $Y_{0 i}$ denotes income from wealth, $w_{i}$ the wage rate of individual $i, l_{i}$ the amount of labour supplied, $T_{i}$ the net lump-sum transfer, and $\alpha_{i}$ an individually varying parameter denoting the importance of income to an individual. In this set-up the disutility of labour in terms of foregone leisure is modelled by subtracting $l_{i}$ from utility. The function $u_{1}($.$) is$ presumed to be concave. The social planner's problem is to maximise $\sum U_{i}$ subject to the constraint that $\sum T_{i}=0$. The solution equation of the social planner is to equalise marginal utility of total income for everybody:

$$
\left.q u_{1}^{\prime}\left(q_{0 i}+y_{i} l_{i}+T_{i}\right)\right)=\sigma_{j} u_{1}^{\prime}\left(\sigma_{j}\left(Y_{0 i}+w_{j} l_{j}+T_{j}\right)\right)
$$

for any combination of $i$ and $j$. This means all the transfers are determined by the transfer to the first individual i.e. by $T_{i}$. The concavity of $u_{1}\left(\right.$.) ensures a unique $T_{1}$ that satisfies the constraint that the sum of the transfers is zero. Standard comparative statics reveal that the transfer $T_{i}$ increases with $\alpha_{i}$ and decreases in $w_{i}$ and $Y_{0 i}$.

To make this model operational, we need an actual measure of utility. In this paper we use life satisfaction as a linear proxy for utility (cf. Layard et al. 2008)). As Clark et al. 
(2008) argue, this is not an innocuous assumption and is not directly testable (to test it, you would need another undoubted measure of utility). What speaks in its favour as a measure of utility is that life satisfaction relates positively to the things that we would expect utility to be related to (health, success, social relations).

What speaks in favour of treating life satisfaction is a cardinal measure of utility is both empirical research that has found you get qualitatively very similar results if you treat life satisfaction as ordinal or cardinal (see Ferrer and Frijters 2004), and an old literature that argues that the logic of language conventions would make the most natural spacing for satisfaction answers equidistance, i.e. the logic of language conventions is that the utility spacing between a happiness level of a 4 and a 5 is the same as between an 8 and a 9. In Van Praag and Frijters (1999) the fairly old experimental literature on this is reviewed more substantively, but the basis of the argument is twofold: for one, if you give individuals a straight line of fixed length and ask them to put ordinally ranked verbal labels (like bad, sufficient, and good) on that line, then there is a strong tendency to have the same spacing between each verbal label, virtually independent of what the verbal labels are and how many there are. Also, individuals can maximise the information they give to respondents by having an equidistance rule for their interpretation of labels (i.e. an outsider makes the last average mistake in assigning an actual number to an ordinal answer if the ordinal answer is equidistance on a cardinal space). What is true though is that such results break down if there is no natural maximum or minimum for the underlying construct, i.e. there has to be something like a maximum amount of happiness and misery for these arguments to hold.

There is much more that can be discussed both in favour and against the cardinality assumption; here we simply postulate it here as a key assumption, though we note that we would get almost the same results if instead of assuming cardinality, we treated the satisfaction answers ordinally and used latent variable techniques (i.e. probits or logits).

If we take an empirical equivalent of equation (1) and make standard functional form assumptions, we can estimate the following life satisfaction regression:

$$
L S_{i t}=X_{i t}, \beta+\left(Z_{i}, y\right) \ln \left(Y_{i t}\right)+\nu_{i}+e_{i t}
$$

where $L S_{i t}$ denotes the life satisfaction of individual $i$ at time $t, X_{i t}, \rho$ denotes the influence of time-varying characteristics $X_{i t}, Y_{i t}$ denotes the income from all sources, $Z_{i}$, is the empirical equivalent of $\alpha_{i}$ and denotes the interaction of fixed observables $Z_{i}$ with income, 
$\nu_{i}$ is a fixed unobservable, and $e_{i t}$ is random noise. Under this empirical specification, optimal transfers would have to equalise:

$$
\frac{\delta L S_{i t}}{\delta T_{i t}}=\frac{\left(Z_{i}^{\prime}\right)}{\left(Y_{i t}+T_{i t}\right)}=C
$$

where $C$ is a constant that uniquely follows from the budget constraint for the transfers $T_{i t}$. In our empirical analyses we will define several taxation-relevant groups $Z_{i}$, and calculate the aggregate optimal transfer, starting from the given levels of actual income in the data. This way we will compare the average of $T$ for different groups. We then compare this with information about the actual net transfers in our Australian setting. We may note here that if one was to treat the life satisfaction question as ordinal, then $L S_{i t}$ would be interpreted as a latent variable but equation (3) would still be the same.

\section{ii. Distortionary transfers}

We can now introduce the idea that transfers have to be paid from distortionary constant marginal taxes $\tau$ rather than individually-specific taxes. We then get the following updated utility function:

$$
\begin{aligned}
& U_{i}=u_{1}\left(\alpha_{i}\left((1-7)\left(Y_{0 i}+w_{i} l_{i}\right)+T_{i}\right)\right)-l_{i} \\
& T_{i} \geq 0 \\
& \sum T_{i}=\sum \pi\left(Y_{0 i}+w_{i} l_{i}\right)
\end{aligned}
$$

where we have overlaid the requirements that transfers have to be non-negative and that the government budget balances. The optimal transfer now has to solve:

$$
\Delta u_{1}^{\prime}\left(\Delta\left((1-\lambda)\left(Y_{0 i}+w_{i} l_{i}\right)+T_{i}\right)\right)=a_{j} u_{1}^{\prime}\left(a\left((1-\lambda)\left(Y_{0 i}+w_{i} l_{i}\right)+T_{i}\right)\right)
$$

which is again uniquely given from the transfer to the first individual $T_{1}$.

However, there are additional complicating factors arising from the fact that there is a solution for each level of $\tau$. The difficulty is that we cannot simply presume that changes in marginal taxation will have no effect on individuals' labour supply and savings behaviour. 
Consequently, we need to model a feed-back effect from changes in marginal taxation to individual household income.

In the empirical application of this complicating factor we follow the dominant literature on optimal taxation (see, for example, Gruber and Saez, 2002) and make the firstorder approximation that $\frac{d \sum r\left(Y_{0 i}+w_{i} l_{i}\right)}{\sum r\left(Y_{0 i}+w_{i} l_{i}\right)}=C \frac{d \tau}{1-\tau}$ implying a constant elasticity of tax returns to marginal taxation. For transparency we take the first-order approximation that all individual incomes react in the same way to marginal taxation.

Therefore we define $Y_{i t}^{*}(t)$ as household income given marginal taxation level $\tau$. Following the constant elasticity approximation, it can be written as:

$$
Y_{i t}^{*}(\tau)=Y_{i t} \frac{(1-7)^{\xi}}{(1-7)^{\zeta}}
$$

where $\tilde{T}$ denotes the marginal level of taxation operating on the whole population at the time of the last interview i.e. the current level of taxation. Hence, $Y_{i}^{*}(\tilde{T})=Y_{i t}$. Here, $1>\xi>0$ denotes the constant elasticity parameter for which we take the best-guess of 0.4 (Gruber and Saez, 2002), which is in the higher range of that found in the empirical literature. If we now consider an increase in marginal taxation in order to pay for the total transfers $\sum T_{i}$ we must take the following steps:

1. Make an initial best guess at the optimal marginal taxation level. Denote that guess by $;$.

2. Calculate $\sum T_{i}=\eta^{*} Y_{i t}^{*}\left(\digamma^{*}\right)$ which is the sum of the transfers. Also calculate for each individual the before-tax-and-transfer income, $Y_{i t}^{*}(\stackrel{*}{*})$.

3. Find the unique $T_{0}$ that solves this programming problem and calculate the total level of utility $\sum U_{i}$ corresponding with $;$.

4. Grid-search for the optimal that maximizes $\sum U_{i}$.

\section{Data}

We estimate the marginal utility of income using data from the Household, Income and Labour Dynamics in Australia (HILDA) survey. HILDA is a household-based longitudinal 
study that is nationally-representative, with the exception of under-sampling individuals living in more remote areas of Australia. It began in 2001 with the survey of 13,969 persons in 7,682 households. Each year since, interviews have been conducted with all willing members of each household who are at least 15 years old at the time of the interview. In these interviews, information is collected on labour force dynamics, education, income, family formation, health and other specialised topics through a combination of interviewer-led and self-completion questionnaires (see Watson and Wooden, 2004, for more details). In this paper we use all of the seven currently available waves of data (2001-07 inclusive) and we focus on all individuals $25+$ who were not students, giving us a working sample of 66,624 observations.

Our measure of life satisfaction comes from responses to the following familiar survey question:

"All things considered, how satisfied are you with your life?"

Respondents are told to:

"Pick a number between 0 and 10 to indicate how satisfied you are" and that "the more satisfied you are, the higher the number you should pick".

The median and modal response to this question equals 8 and the distribution of responses is negatively skewed, with over three quarters choosing 7 or above. Average life satisfaction for the total sample and for each group used in the empirical analysis is shown in Table 1. These figures show that life satisfaction is highest for those aged 65+, those who are married, those who live in rural locations and those with no limiting illness. In terms of age group, individuals aged 35-44 report the lowest levels of life satisfaction. Also reported in Table 1 is the mean household income after government taxes and monetary transfers for each group. Individuals aged 35-54, those who are married and those with dependent children have the highest incomes, while those of pensionable age and those with a limiting health condition have the lowest incomes.

An important question is whether income and life satisfaction are approximately linearly related, as has been assumed in the models above and as has been standard in the literature. Figure 1 shows a Kernel plot relating the income of a household and its life satisfaction. Income is on a logarithmic scale and the graph shows both a single line that denotes the Kernel plot as well as a shaded area that denotes the $95 \%$ confidence interval. The majority of the data lies in the region where log-income is 10 to 12 , where the relationship is quite linear and the confidence interval is very small. 


\section{Analysis}

Table 2 presents estimates of the life satisfaction regression expressed in equation (3). As is becoming standard in this literature, and for ease of calculation, we treat the 0-10 ordinal life satisfaction scale as continuous and cardinal (see Ferrer-i-Carbonel and Frijters, 2004). While our calculations and following discussion are based on the fixed-effects regression estimates, we also show the OLS estimates to highlight the large extent to which the estimates differ, in particular with respect to the income interaction terms. The regressions include a set of timevarying controls that are now reasonably standard in fixed-effects analyses (see, for example, Clark et al., 2008b; Frijters et al., 2004; Winkelmann and Winkelmann, 1998). The controls included are: age group (25-34, 35-44, 45-54, 55-64 and 65+ (omitted category)), marital status, pre-school and school-age dependent child, reside in rural location, limiting chronic illness, current employment status (employed, unemployed, retired) and the log of household income. The regression also includes interactions between log income and dummy variables for age groups, marital status, dependent child, rural location and limiting illness. It is the inclusion of the interaction terms that allows the marginal utility of income to differ across (potentially taxable) groups.

The top panel contains estimated impacts of income and its interactions with individual-level characteristics $(\hat{y})$, and the bottom panel contains estimated impacts of all other time-varying characteristics $(\hat{B})$. With respect to $\hat{\hat{s}}$ our results are similar to previous fixed-effects life satisfaction findings for Australia and other countries, with satisfaction gains found for higher household income, marriage and employment, and satisfaction losses found for limiting illness and unemployment. We also find a life satisfaction gain from becoming retired and moving to a rural location.

The fixed-effects estimates of the income interactions $\left(Z_{i}, \hat{y}\right)$ imply that married individuals have a particularly low marginal utility of money (-0.124). The estimates also imply that those aged between 25 and 54, especially those aged between 35 and 44 (0.115), have a higher utility of money than older individuals. Importantly, we find no significant differences in the marginal utility of money between individuals with and without dependent children (either in the OLS or Fixed-Effects models), between individuals residing in rural and urban locations, and between healthy individuals and those with a limiting illness.

Using the estimated marginal utilities from Table 2, Column 1 of Table 3 presents mean values of the estimated optimal transfers. The optimal transfers are calculated under the assumption that we (the Government/Planner) can organise lump-sum transfers without any 
behavioural effects i.e. without marginal taxation and the subsequent labour supply responses. Column 2 presents average post-transfer incomes within each group, where the groups are not mutually exclusive. The post-transfer incomes can be compared with the actual average disposable incomes for the various groups in Table 1. The optimal transfers are highest for single parents with a dependent child $(\$ 73,569)$. The optimal transfers are lowest for married persons aged 55-64 without dependent children. On average these persons are taxed $\$ 50,860$. These results reflect differences in initial levels of disposable income, shown in Table 1, and differences in estimated marginal utilities, shown in Table 2. The large taxation on married persons aged 55-64 without dependent children, for instance, derives from the fact that their estimated marginal utility from income is almost zero, and therefore in an optimal transfer system should end up with almost nothing.

Column 3 of Table 3 presents mean values of the estimated optimal transfers when we presume that transfers must be paid from marginal taxation with distortionary behavioural consequences. These values are calculated using a starting value of $34 \%$ as the current level of taxation. This estimated figure comes from Hallam and Weber (2007) who follow the Prescott (2004) methodology of calculating marginal tax rates in the United States, Japan, Canada and Europe. With a labour elasticity value of 0.4 the optimal marginal taxation level turns out to be $58 \%$, which corresponds to an additional $24 \%$ taxation. This is a high figure but not unheard of as it corresponds to the marginal taxation levels of the Scandinavian welfare states of the 1980s (and even in 2009, the top marginal rate in Sweden was 56.5\%).

If we take account of the behavioural effects of taxation, optimal transfers and net incomes become smaller in magnitude than is the case with lump-sum transfers. Net incomes decrease because the total size of the economy shrinks with every dollar taxed. Transfers decrease because the negative productivity effects mean it is sub-optimal to tax high income individuals to the same extent as with lump sum taxation. Another change with marginal taxation is that net transfers for those aged $65+$ have changed sign. With lump sum taxes those aged $65+$ were taxed $\$ 5,408$, but with marginal taxation those aged $65+$ received $\$ 1,591$. The change arises because this age group contains some poor individuals who benefit from transfers and some rich individuals who cannot be taxed as much in the absence of lump sum taxes. The reduction in taxes imposed on rich older individuals is larger than the reduction in transfers given to poor older individuals, hence the change in sign. Furthermore, this change has meant that married persons aged 55-64 without a dependent child is no longer the group that receives the most negative transfer. This group is now married persons with a dependent child $(-\$ 13,971)$. Despite these differences, however, the group that receives the 
most positive transfer is unchanged. Single parents with a dependent child again receive the largest net transfer $(\$ 25,567)$.

We can now make a comparison with observed transfers in Australia. Column 5 of Table 3 shows the actual level of transfers for various groups in Australia, as reported by the Australian Bureau of Statistics (ABS, 2007). ${ }^{2}$ It is important to bear in mind that our estimated 'optimal transfers' are levels of additional transfers that would have to be made over and above the present level of transfers.

The actual transfers and the happiness optimising transfers are $\$ 24,630$ and the optimising transfers are $\$ 25,567$. The groups that should be taxed the most (married persons with dependent child, married persons aged 55-64 without a dependent child, persons aged 55-64 and persons aged 45-54) already face a negative net transfer and are therefore taxed, but much less than would be optimal.

The biggest differences are for particular ages. For single persons aged 25-34 without a child, the actual transfers are $-\$ 10,303$ (they are taxed) whilst the optimising transfers are $\$ 13,500$ (a subsidy). This considerable divergence is caused by the fact that our model predicts that young single persons have a high marginal utility of income, whereas Australia's tax and transfer system largely provides transfers to families and the elderly. In addition, Table 3 shows that those aged 35-44 should receive more transfers since they have a high marginal utility of income, yet they are currently taxed more highly. Interestingly, these calculations imply that those aged above 65 would need to be more highly taxed because of their low marginal utility of income but they get very high transfers.

\section{Conclusion}

The last decade has witnessed a tremendous growth in interest by economists in testing competing theories and providing new insights into economic behaviour by using data on life satisfaction or happiness, where such survey responses are taken to be direct proxies for utility. In this paper we contribute to this literature by using life satisfaction data to examine the issue of optimal taxation. We find that young and middle aged individuals have the highest marginal satisfaction of income and that married individuals, especially married individuals with young children, have the lowest. Under an optimal scheme, those with the

\footnotetext{
${ }^{2}$ The Australian Bureau of Statistics (2007) estimates the effects of government benefits and taxes on the distribution of income among private households in Australia in 2003-04. The study excludes government taxes and expenditure that do not relate directly to households, such as government revenue from corporate taxes and government spending on defence. We include expenditures on amenities, like schooling, because they substitute for private payments.
} 
lowest marginal satisfaction with income would be taxed more heavily in favour of those with the higher marginal satisfaction with income. In this paper we have used Australian panel data, but we believe this methodology could be reasonably applied to other countries.

The significance of these results for actual policy is probably not in providing direct estimates of how high transfers should be, because there are many ways in which such taxes and transfers would lead to unintended behavioural distortions. For example, married people can get nominally divorced in order to be treated as singles, and contrary to our simplistic model, labour supply reactions may be stronger for some groups than the average reaction we have allowed for. The results should therefore mainly be taken as indicative of whether or not current transfer policies manage to tax those with little marginal satisfaction with income to those with high marginal satisfaction with income. In broad terms, this does seem to be the case. However, this conclusion does not hold for younger Australians, particularly young single Australians. This group is taxed far more heavily than their high marginal satisfaction with income would predict. 


\section{References}

Australian Bureau of Statistics (2007). Government Benefits, Taxes and Household Income. Cat No 6537.0, ABS, Canberra.

Borjas, GJ. (2004), Labor Economics, Third Edition, Mc-Graw Hill.

Carroll, N., Frijters, P. and Shields, MA. (2009). Quantifying the costs of drought: New evidence from life satisfaction data. Journal of Population Economics, vol. 22, pp. 445461.

Clark, A., Frijters, P. and Shields, MA. (2008). Relative income, happiness and utility: An explanation for the Easterlin Paradox and other puzzles. Journal of Economic Literature, vol. 46, pp.95-144.

Clark, A., Diener, E., Georgellis, Y. and Lucas, R. (2008b). Lags and leads in life satisfaction: A test of the baseline hypothesis. Economic Journal, vol. 118, pp. F222F239.

Di Tella, R. and MacCulloch, R. (2006). Some uses of happiness data in economics. Journal of Economic Perspectives, vol. 20, pp. 25-46.

Faulk, D., Martinez-Vazquez, J. Wallace, S. (2007). "Using Human-Capital Theory to establish a Potential-Income Tax," FinanzArchiv: Public Finance Analysis, pp 415-35.

Ferrer-i-Carbonel, A. and Frijters, P. (2004). The effect of methodology on the determinants of happiness. Economic Journal, vol. 114, pp. 641-659.

Ferrer-i-Carbonell, A, and van Praag, BMS (2002). "The subjective costs of health losses due to chronic diseases. An alternative model for monetary appraisal," Health Economics, vol. 11(8), pages 709-22.

Frey, B. and Stutzer, A. (2002). What can economists learn from happiness research? Journal of Economic Literature, vol. 40, pp. 402-435.

Frey, B., Luechinger, S. and Stutzer, A. (2007). Calculating tragedy: Assessing the costs of terrorism. Journal of Economic Surveys, vol. 21, pp. 1-24.

Frey, B., Luechinger, S. and Stutzer, A. (2009). The life satisfaction approach to valuing public goods: The case of terrorism. Public Choice, vol. 138, pp. 317-345.

Frijters, P., Haisken-DeNew, J. and Shields, MA. (2004). Money does matter! Evidence from increasing real income and life satisfaction in East Germany following reunification. American Economic Review, vol. 94, pp.730-740.

Frijters, P. and Gregory, R. (2006). From golden age to golden age: Australia's Great Leap forward. Economic Record, vol. 82, pp. 207-225.

Gruber, J. and Saez, E. (2002). The elasticity of taxable income: Evidence and implications. Journal of Public Economics, vol. 84, pp. 1-32.

Hallam, A. and Weber, EJ. (2007). Labour taxes and work hours in Australia. Working Papers no. 07-09, University of Western Australia, Department of Economics.

Layard, R., Mayraz, G., and Nickell, S., (2008). "The marginal utility of income," Journal of Public Economics, vol. 92(8-9), pages 1846-1857

Luechinger, S., Meier, S. and Stutzer, A. (2008). Bureaucratic rents and life satisfaction. Journal of Law, Economics and Organization, vol. 24, pp. 476-488.

Meier, S. and Stutzer, A. (2007). Is volunteering rewarding in itself? Economica, vol. 75, pp. 39-59.

Mirrlees, JA., (1971). "An Exploration in the Theory of Optimum Income Taxation," Review of Economic Studies, vol. 38(114), pages 175-208

Prescott, EC. (2004). Why do Americans work so much more than Europeans? Federal Reserve Bank of Minneapolis Quarterly Review, vol. 28, pp. 2-13.

Plug, EJS., van Praag, BMS, and Hartog, J (1999) "If we knew ability, how would we tax individuals?," Journal of Public Economics, vol. 72(2), pages 183-211. 
Saez, E. (2001). Using elasticities to derive optimal income tax rates. Review of Economic Studies, vol. 68, pp. 205-229.

Stutzer, A. and Frey, B. (2008). Stress that doesn't pay: The commuting paradox. Scandinavian Journal of Economics, vol. 110, pp. 339-366.

Tinbergen, J. (1970) 'Belasting op bekwaamheid [Tax on ability].' Intermediair 30(6), 1-3

Van Praag, BMS. and Baarsma, BE. (2005). Using happiness surveys to value intangibles: The case of airport noise. Economic Journal, vol. 115, pp. 224-246.

Van Praag, BMS., and Frijters, P. (1999), 'The measurement of welfare and well-being; the Leyden approach', in Kahneman, D., Diener, E., Schwarz, N. (eds), Well-being: the foundations of hedonic psychology, New York: Russel Sage Foundation, pp. 413-432. Handbook.

Watson, N. and Wooden, M. (2004). The HILDA survey four years on. Australian Economic Review, vol. 37, pp. 343-349.

Winkelmann, L. and Winkelmann, R. (1998). Why are the unemployed so unhappy? Evidence from panel data. Economica, vol. 65, pp. 1-17. 
Figure 1: Relationship between Log Income and Life Satisfaction

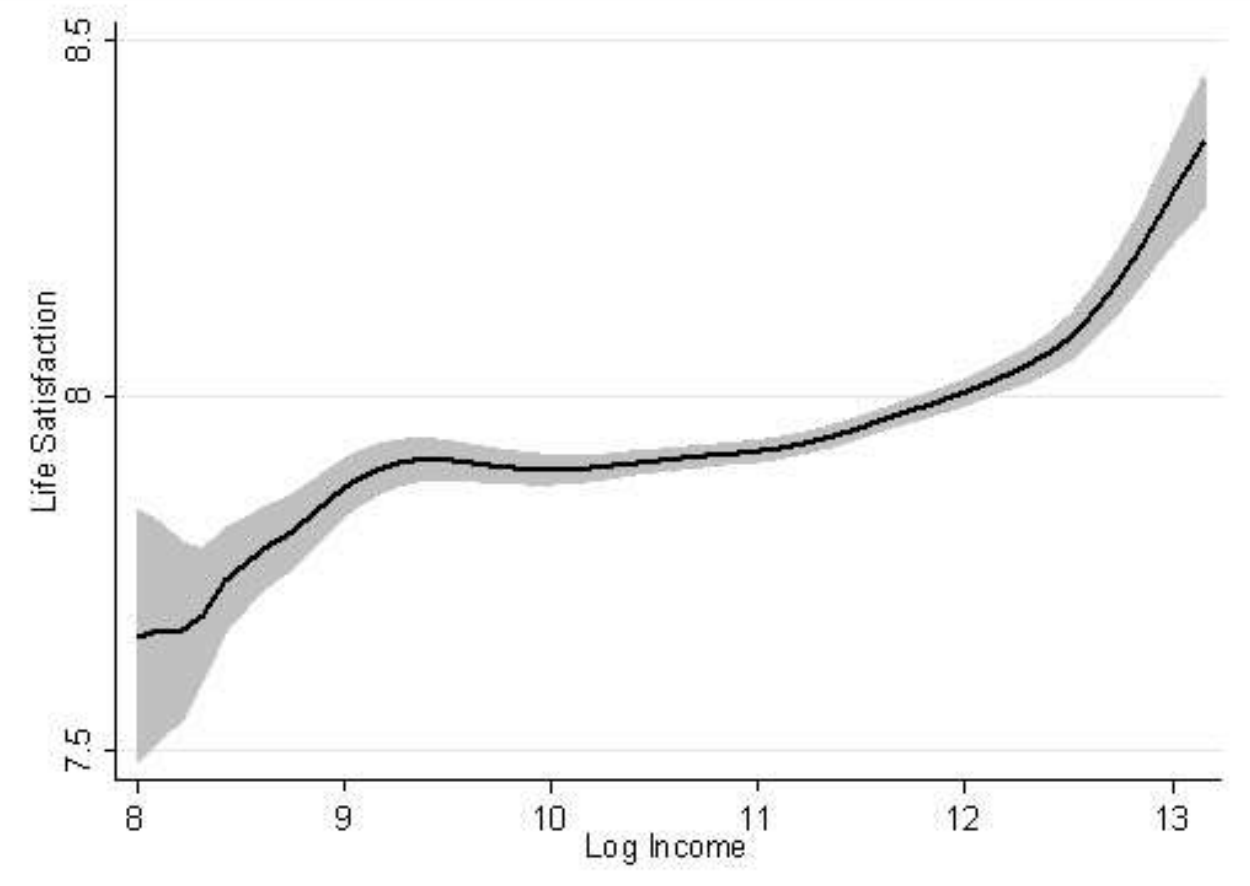


Table 1: Descriptive Statistics by Group

\begin{tabular}{|c|c|c|c|c|c|c|}
\hline & \multicolumn{2}{|c|}{ Proportion } & \multicolumn{2}{|c|}{ Mean Life Satisfaction } & \multicolumn{2}{|c|}{ Mean Income } \\
\hline All & 1.000 & & 7.928 & $(0.006)$ & 57,572 & (161.7) \\
\hline Aged 25-34 & 0.186 & $(0.002)$ & 7.790 & $(0.013)$ & 63,258 & $(310.6)$ \\
\hline Aged 35-44 & 0.235 & $(0.002)$ & 7.693 & $(0.012)$ & 67,189 & $(330.6)$ \\
\hline Aged 45-54 & 0.213 & $(0.002)$ & 7.764 & $(0.013)$ & 69,238 & $(368.3)$ \\
\hline Aged 55-64 & 0.163 & $(0.001)$ & 8.050 & $(0.015)$ & 55,366 & (458.0) \\
\hline Aged 65+ & 0.204 & $(0.002)$ & 8.398 & (0.013) & 30,870 & $(221.3)$ \\
\hline Married & 0.615 & $(0.002)$ & 8.105 & $(0.007)$ & 64,851 & $(215.8)$ \\
\hline Single & 0.246 & $(0.002)$ & 7.648 & (0.014) & 37,590 & (241.5) \\
\hline Dependent child 0-4 & 0.147 & $(0.001)$ & 7.866 & $(0.015)$ & 66,798 & (390.7) \\
\hline Dependent child 5-14 & 0.294 & $(0.002)$ & 7.815 & $(0.011)$ & 72,427 & (299.3) \\
\hline No dependent child & 0.562 & $(0.002)$ & 8.003 & $(0.008)$ & 47,404 & (203.6) \\
\hline Regional residence & 0.390 & $(0.002)$ & 8.072 & $(0.010)$ & 50,245 & (216.9) \\
\hline Metropolitan residence & 0.610 & $(0.002)$ & 7.835 & $(0.008)$ & 62,263 & $(222.8)$ \\
\hline Limiting illness & 0.216 & $(0.002)$ & 7.475 & $(0.016)$ & 39,404 & $(268.4)$ \\
\hline Non-limiting illness & 0.784 & $(0.002)$ & 8.053 & $(0.006)$ & 62,590 & $(186.7)$ \\
\hline
\end{tabular}

Notes: Figures in parentheses are standard errors. Sample size equals 66624. Income values represent real household income after taxes and transfers in Australian dollars. 
TABLE 2: Life Satisfaction Estimates

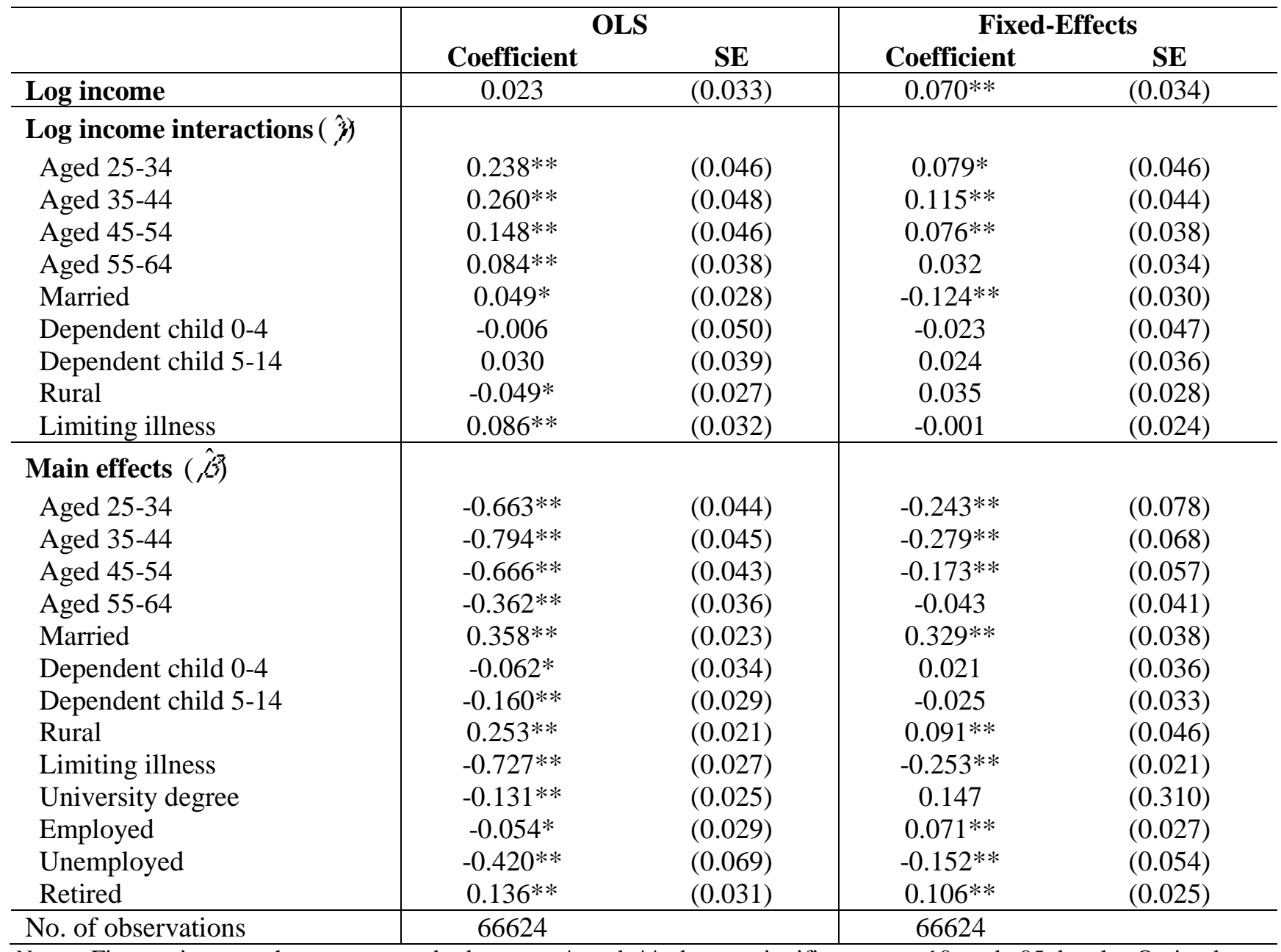

Notes: Figures in parentheses are standard errors. ${ }^{*}$ and $* *$ denote significance at .10 and .05 levels. Omitted categories are age 65+, not married, no dependent children, city or urban location and no limiting illness. 
TABLE 3: Optimal Transfers With and Without Marginal Taxation

\begin{tabular}{l|cc|ccc}
\hline & \multicolumn{2}{|c|}{ Without Marginal Taxation } & \multicolumn{3}{c}{ With Marginal Taxation } \\
& Transfer & Net Income & Transfer & Net Income & $\begin{array}{c}\text { Estimated } \\
\text { Actual } \\
\text { Transfers }\end{array}$ \\
\hline Aged 25-34 & & & & & \\
Aged 35-44 & 7,229 & 70,487 & 826 & 53,622 & $-6,423$ \\
Aged 45-54 & 21,563 & 88,752 & 3,435 & 59,511 & -891 \\
Aged 55-64 & $-5,703$ & 63,536 & $-2,904$ & 54,883 & $-7,380$ \\
Aged 65+ & $-25,067$ & 30,299 & $-4,022$ & 42,187 & -746 \\
Married & $-5,408$ & 25,462 & 1,591 & 27,355 & 19,213 \\
Single & $-38,272$ & 26,580 & $-12,143$ & 41,982 & - \\
Dependent child 0-4 & 62,899 & 100,489 & 22,391 & 53,764 & - \\
Dependent child 5-14 & $-23,275$ & 43,523 & $-7,116$ & 48,635 & - \\
No dependent child & $-5,056$ & 67,372 & $-4,465$ & 55,983 & - \\
Regional residence & 8,853 & 56,257 & 4,220 & 43,783 & - \\
Metropolitan residence & 17,719 & 67,963 & 5,407 & 47,342 & - \\
Limiting illness & $-11,335$ & 50,928 & $-3,446$ & 48,520 & - \\
Non-limiting illness & 13,401 & 52,805 & 6,887 & 39,774 & - \\
\hline Single with dependent child & $-3,696$ & 58,895 & $-1,890$ & 50,348 & - \\
Married with dependent child & 73,569 & 119,692 & 25,567 & 64,061 & 24,630 \\
Aged 25-34, single & $-36,930$ & 39,175 & $-13,971$ & 49,547 & -968 \\
$\quad$ without dependent child & 54,105 & 114,265 & 13,500 & 63,710 & $-10,303$ \\
Aged 55-64, married & & & & & - \\
without dependent child & $-50,860$ & 4,405 & $-11,053$ & 35,071 & $-3,307$ \\
\hline
\end{tabular}

Notes: Figures in columns 1-4 are mean estimated values. Net income values represent income after estimated transfers and taxes in Australian dollars. Figures in column 5 are from ABS (2007). 


\section{University Library}

\section{- M M N E R VA A gateway to Melbourne's research publications}

Minerva Access is the Institutional Repository of The University of Melbourne

Author/s:

Frijters, P;Johnston, DW; Shields, MA

Title:

The Optimality of Tax Transfers: What does Life Satisfaction Data Tell Us?

Date:

2012-10-01

Citation:

Frijters, P., Johnston, D. W. \& Shields, M. A. (2012). The Optimality of Tax Transfers:

What does Life Satisfaction Data Tell Us?. JOURNAL OF HAPPINESS STUDIES, 13 (5), pp.821-832. https://doi.org/10.1007/s10902-011-9293-3.

Persistent Link:

http://hdl.handle.net/11343/282608 